\title{
Early- and Long-Term Outcomes After Surgery for Acute Type A Aortic Dissection in Patients Aged 45 Years and Younger
}

\author{
Naoyuki Kimura, MD; Masashi Tanaka, MD, PhD; Koji Kawahito, MD, PhD; \\ Satoshi Itoh, MD; Homare Okamura, MD; Atsushi Yamaguchi, MD, PhD; \\ Takashi Ino, MD, PhD; Hideo Adachi, MD, PhD
}

\begin{abstract}
Background: Acute type A aortic dissection (AAAD) is rare in young people. The early- and long-term outcomes after surgery for $A A A D$ in patients aged $\leq 45$ years was investigated.

Methods and Results: Subjects were 355 patients who had undergone emergency surgery for AAAD. The patients were grouped as those aged $\leq 45$ years ( $n=30$; mean age, 38.3 years; younger group) and those aged $>45$ years $(n=325$; mean age, 65.3 years; older group). Clinical and prognostic variables were compared between the groups. Male sex, Marfan syndrome, and severe aortic regurgitation were more prevalent in the younger group. In-hospital mortality $(16.7 \%$ vs. $8.6 \%, \mathrm{P}=0.15)$ and postoperative patency of the distal aorta $(90.8 \%$ vs. $59.1 \%, P<0.01$ ) were more frequent in the younger group. The leading causes of late death were aortic rupture in the younger group $(75.0 \%)$ and malignancy in the older group $(27.5 \%)$. Although actuarial survival at 10 years was similar (64.5\% vs. $62.5 \%)$, freedom from aortic reoperation at 10 years was decreased in the younger group (49.4\% vs. 85.0\%, $\mathrm{P}=0.012)$. A distal aorta $>45 \mathrm{~mm}(\mathrm{P}<0.001)$, Marfan syndrome $(\mathrm{P}<0.01)$, and age $\leq 45$ years $(\mathrm{P}=0.045)$ were shown to be independent risk factors for reoperation.
\end{abstract}

Conclusions: Early- and long-term surgical outcomes are not better for patients $\leq 45$ years, and the risk for reoperation is high in this group. Careful follow up is important in young patients with AAAD. (Circ J 2011; 75: 2135-2143)

Key Words: Aorta; Dissection; Reoperation; Young

W ith advances in diagnosis and perioperative care, ${ }^{1,2}$ surgical outcomes have improved substantially among patients with aortic dissection..$^{3,4}$ Aortic dissection typically occurs in older hypertensive patients, with its peak incidence in the 6th decade of life. Aortic dissection in young patients is relatively rare. Puranik et al reported that, out of 427 non-traumatic sudden deaths that occurred over a 10-year period in persons aged 5-35 years, aortic dissection accounted for only $5.4 \% .^{5}$ According to the International Registry of Acute Aortic Dissection (IRAD) data published in 2004, only $7 \%$ (68 of 951 patients with acute aortic dissection) were younger than 40 years. ${ }^{6}$ Aortic dissection in this subgroup is most often related to an underlying connective tissue disease, such as Marfan syndrome (MFS); $;{ }^{6,7}$ however, some younger patients do not have any underlying connec- tive tissue disease. Clinical outcomes among patients with MFS and acute type A aortic dissection (AAAD) are generally known, ${ }^{8-12}$ but there are few reports based solely on age rather than etiology that describe patient characteristics and treatment outcomes among young patients with AAAD.

With the general increase in the human lifespan, the number of elderly patients undergoing surgery for AAAD is increasing; thus, many investigators have studied and described the clinical characteristics and surgical outcomes of elderly patients with AAAD. ${ }^{13-15}$ The optimal treatment for elderly patients with AAAD remains controversial, but there are reports of acceptable surgical outcomes for such patients. ${ }^{14,15}$ In contrast, little is known about surgical outcomes among young patients with AAAD. Aortic dissection remains one of the most serious cardiovascular diseases, and when it

Received December 6, 2010; revised manuscript received March 26, 2011; accepted April 17, 2011; released online June 28 , 2011 Time for primary review: 30 days

Department of Cardiovascular Surgery, Saitama Medical Center, Jichi Medical University, Saitama (N.K., S.I., H.O., A.Y., T.I., H.A.); Department of Cardiovascular Surgery, Shonan Kamakura General Hospital, Kamakura (M.T.); and Department of Cardiac Surgery, Kashiwa Hospital, Jikei University School of Medicine, Kashiwa (K.K.), Japan

This paper was presented at the AATS Aortic Symposium 2010 (April 29-30, 2010, New York, NY, USA).

Mailing address: Naoyuki Kimura, MD, Department of Cardiovascular Surgery, Saitama Medical Center, Jichi Medical University, 1-847 Amanuma-cho, Omiya-ku, Saitama 330-0834, Japan. E-mail: kimura-n@omiya.jichi.ac.jp

ISSN-1346-9843 doi:10.1253/circj.CJ-10-1222

All rights are reserved to the Japanese Circulation Society. For permissions, please e-mail: cj@j-circ.or.jp 
occurs in young patients, it has a disproportionate impact on the community. We conducted a comparative study to elucidate the clinical characteristics of young patients with AAAD as well as in-hospital and long-term surgical outcomes among these patients.

\section{Methods}

Between January 1991 and June 2008, 355 consecutive patients (188 men, 167 women; mean age, 63.0 \pm 12.1 years) underwent emergency surgery for AAAD at Saitama Medical Center, Jichi Medical University. Aortic dissection was diagnosed on the basis of enhanced computed tomography (CT) or echocardiography findings. Surgery was performed in all patients within 14 days of the acute onset of symptoms, with $91.3 \%(324 / 355)$ of these surgeries being performed within $48 \mathrm{~h}$ of onset. The remaining $8.7 \%(31 / 355)$ of patients underwent surgery more than $48 \mathrm{~h}$ after symptom onset due to a delay in the diagnosis of AAAD and in referral to our hospital. Of the 355 patients, 4 patients $(1.1 \%)$ were $\leq 30$ years of age, $13(3.7 \%)$ were $\leq 40$ years, and $30(8.4 \%)$ were $\leq 45$ years. Therefore, we used 45 years as the cut-off age for comparison between younger patients and older patients. Patients were classified into 2 groups: those aged $\leq 45$ years $(n=30$; mean age, $38 \pm 6.3$ years, range $23-45$ years; younger group) and those aged $>45$ years $(n=325$; mean age, $65 \pm 9.8$ years, range 46-92 years; older group). Eleven of the 355 patients had MFS, which had been diagnosed on the basis of 6 organ systems, that is, the skeletal, ocular, cardiovascular, nervous, pulmonary, and skin/integumentary systems, as well as a family/ genetic history with corresponding major and minor criteria. Patients with traumatic aortic dissection were excluded from the study. The study followed the ethics guidelines of the institutional review board of Jichi Medical University.

Our hospital has routinely checked patients' general postoperative health status once every 3 years by mailing a questionnaire to all patients who have undergone surgery for AAAD since 1989. The questionnaire includes a space where patients can provide informed consent for use of their medical records for research purposes. The return rate is greater than $90 \%$. If patients do not return the questionnaire, we contact them by telephone to obtain health status information as well as the informed consent. Thus, all patients included in the study had previously granted permission for use of their medical records for research purposes.

Operative techniques have evolved somewhat over the 1991-2008 period. However, the basic surgery for AAAD involves replacement of the ascending aorta and resection of the primary entry site by open distal anastomosis under deep hypothermic circulatory arrest. During the 1991-1996 period, ringed intraluminal graft insertion was performed in 16 patients. The site of arterial cannulation has changed over time, with preferential use of the subclavian artery over that of the femoral artery in recent years. Once cardiopulmonary bypass is established, systemic cooling is started. The aorta is clamped after onset of ventricular fibrillation. During the cooling period, the proximal stump is trimmed, and 2 Teflon felt strips (DuPont, Parkersburg, WV, USA) are placed, 1 inside and 1 outside the aorta, for reinforcement. The aortic arch is then explored under circulatory arrest at a rectal temperature of $20^{\circ} \mathrm{C}$. The extent of graft interposition is determined on the basis of operative findings. If the entry site is located in the ascending aorta, ascending aorta replacement (including hemiarch replacement) is performed by the open aorta technique. If the entry site is present in or extends into the aortic arch, partial or total arch replacement is performed with selective cerebral perfusion. When the entry site cannot be identified or is identified in the descending thoracic aorta by transesophageal echocardiography, we simply replace the ascending aorta. The placement technique always includes the interposition of woven collagen-impregnated or albumin-sealed grafts with Teflon felt reinforcement of the aortic stumps. Gelatinresorcin-formalin adhesive is not used. Aortic root replacement with a composite graft and reimplantation of the coronary arteries by the modified Bentall procedure is performed in patients with conspicuous dilation of the aortic root.

For all survivors, CT scanning was performed within 1 month after surgery. The aortic diameter was measured at 4 different levels, that is, at the aortic base, aortic arch, and proximal (at the level of the aortic isthmus) and distal (at the level of the supra-diaphragm) descending aorta. A patent false lumen was defined as a false lumen that was enhanced during delayed-phase CT (90-120s after the start of injection of contrast medium). However, in patients who did not undergo a delayed-phase CT, patency of the false lumen was judged on the basis of early-phase data. If contrast medium was found anywhere in the distal aorta, the false lumen was considered patent. Thus, a partially thrombosed false lumen in the distal aorta was judged as a patent false lumen.

In-hospital data were obtained by a review of patients' hospital records. Follow-up data including survival time, general health condition, aortic reoperation or rupture, and cause of death were obtained from our outpatient clinic, through written or telephone contact with patients or relatives, or from local cardiologists. The average follow-up period was $4.8 \pm$ $4.1(0.2-18.7)$ years, and follow-up information was obtained for $99.1 \%(319 / 322)$ of the patients who were discharged from the hospital.

In-hospital mortality was defined as any death that occurred during the initial hospitalization or within 30 days after hospital discharge. All values are expressed as mean \pm SD. Betweengroup differences in clinical variables were analyzed by the $\chi^{2}$ or Fisher's exact test or by an unpaired t-test or MannWhitney U test. To identify independent risk factors for 30-day mortality for all patients who underwent surgery for AAAD, multivariate logistic regression analysis was performed, and the following factors were examined: age, sex, obesity (body mass index $>30 \mathrm{~kg} / \mathrm{m}^{2}$ ), MFS, bicuspid aortic valve, hypertension, diabetes, current smoking, chronic obstructive airway disease, chronic hemodialysis, previous cardiac surgery, history of ischemic heart disease, history of cerebral vascular disease, severe aortic valve insufficiency, shock (systolic blood pressure $<90 \mathrm{mmHg}$ ), cardiac tamponade, coma, visceral ischemia, limb ischemia, hemopericardium, location of the primary intimal tear, DeBakey classification, arterial cannulation site, surgical procedure, prolonged caridiopulmonary bypass time ( $>180 \mathrm{~min})$, prolonged myocardial ischemia time $(>120 \mathrm{~min})$, prolonged operation time $(>360 \mathrm{~min})$, and resection of the primary entry tear. Similarly, the influence of these factors together with others reflecting the postoperative course, such as postoperative complications, distal aortic diameter, patency of the residual false lumen, and use of antihypertensive drugs or warfarin, on late survival and aortic reoperation was examined by means of Cox proportional hazards regression analysis.

Freedom from time-related events was estimated by using the non-parametric actuarial Kaplan-Meier method and analyzed by a log-rank test. $\mathrm{P}<0.05$ was considered statistically significant. All statistical analyses were performed with SPSS 17.0 for Windows software (SPSS, Inc, Chicago, IL, USA). 


\begin{tabular}{|c|c|c|c|}
\hline Characteristic & $\begin{array}{c}\text { Younger group } \\
\text { Age } \leq 45 \text { years } \\
(n=30)\end{array}$ & $\begin{array}{l}\text { Older group } \\
\text { Age >45 years } \\
(n=325)\end{array}$ & $P$ value \\
\hline \multicolumn{4}{|l|}{ Clinical characteristics } \\
\hline Age (years, mean $\pm \mathrm{SD}$ ) & $38.3 \pm 6.3$ & $65.3 \pm 9.8$ & $<0.001$ \\
\hline Male sex & 28 (93.3) & $160(49.2)$ & $<0.001$ \\
\hline Marfan syndrome & $8(26.7)$ & $3(0.9)$ & $<0.001$ \\
\hline Bicuspid aortic valve & $1(3.3)$ & $2(0.6)$ & NS \\
\hline Hypertension & $16(53.3)$ & $224(68.9)$ & NS \\
\hline Diabetes & $2(6.7)$ & $22(6.8)$ & NS \\
\hline Current smoking & $19(63.3)$ & $102(31.4)$ & 0.003 \\
\hline History of CAD & $1(3.3)$ & $16(4.9)$ & NS \\
\hline History of CVD & $0(0)$ & $32(9.8)$ & NS \\
\hline COPD & $0(0)$ & $16(5.2)$ & NS \\
\hline Chronic hemodialysis & $0(0)$ & $6(1.9)$ & NS \\
\hline Reoperation & $1(3.3)$ & $3(0.9)$ & NS \\
\hline \multicolumn{4}{|l|}{ Dissection characteristics } \\
\hline Severe aortic regurgitation & $9(30.0)$ & $30(9.2)$ & 0.001 \\
\hline Shock (systolic BP <90 mmHg) & $5(16.7)$ & $110(34.0)$ & NS \\
\hline TIA or neurological deficits & $2(6.7)$ & $53(16.3)$ & NS \\
\hline Myocardial ischemia & $0(0)$ & $23(7.1)$ & NS \\
\hline Visceral ischemia & $1(3.3)$ & $11(3.4)$ & NS \\
\hline Limb ischemia & $5(16.7)$ & $34(11.2)$ & NS \\
\hline Aortic diameter $>60 \mathrm{~mm}$ & $8(15.4)$ & $57(17.5)$ & NS \\
\hline Hemopericardium & $15(50.0)$ & $210(64.6)$ & NS \\
\hline \multicolumn{4}{|l|}{ Location of intimal tear } \\
\hline Aortic root-ascending aorta & $19(63.3)$ & $201(61.8)$ & NS \\
\hline Aortic arch & $4(13.3)$ & $37(11.4)$ & NS \\
\hline Unidentified (or descending aorta) & $7(23.3)$ & $87(26.8)$ & NS \\
\hline \multicolumn{4}{|l|}{ DeBakey classification } \\
\hline Type I & $23(76.7)$ & $207(63.6)$ & NS \\
\hline Type II & $0(0)$ & $31(8.7)$ & NS \\
\hline Type III b retrograde & $7(23.3)$ & $87(26.8)$ & NS \\
\hline
\end{tabular}

Number (and percentage) of patients are shown unless otherwise indicated.

$\mathrm{CAD}$, coronary artery disease; CVD, cerebrovascular disease; COPD, chronic obstructive pulmonary disease; $\mathrm{BP}$, blood pressure; TIA, transient ischemic attack.

\section{Results}

Clinical and dissection characteristics of the 2 groups are shown in Table 1. In comparison to the older group, the younger group had a greater percentage of male patients $(\mathrm{P}<0.001)$, patients with MFS $(\mathrm{P}<0.001)$, current smokers $(\mathrm{P}=0.003)$, and patients with severe aortic regurgitation $(\mathrm{P}=0.001)$. Surgical variables are shown per group in Table 2 . Regarding proximal reconstruction, 17 patients underwent the modified Bentall procedure, and 3 patients underwent separate aortic valve replacement. Regarding distal replacement, 287 patients underwent ascending aorta or hemiarch replacement, and 52 patients underwent aortic arch replacement. The entry resection rate was $72.3 \%(257 / 355)$, and the reasons for non-resection were type IIIb dissection $(88.8 \%, 87 / 98)$ and type I or II dissection treated by ringed graft insertion $(11.2 \%, 11 / 98)$. Three of the 90 patients with type III dissection underwent a total aortic arch replacement. Aortic root replacement was performed for proximal reconstruction more frequently in the younger group than in the older group $(\mathrm{P}<0.001)$, and the average cardiopulmonary bypass time $(\mathrm{P}=0.001)$, myocardial ischemia time $(\mathrm{P}=0.001)$, and operation time $(\mathrm{P}=0.002)$ were significantly longer in the younger group than in the older group.
Early outcomes and causes of in-hospital death are shown in Table 3. Overall in-hospital mortality was 9.3\% (33/355): $16.7 \%(5 / 30)$ in the younger group and $8.6 \%(28 / 325)$ in the older group, without a significant difference $(\mathrm{P}=0.15)$. The leading cause of death was cardiac failure in both groups, and the second leading cause of death was postoperative rupture of the aorta, ${ }^{16}$ with no significant between-group differences in the causes of in-hospital death. Logistic regression analysis showed shock [odds ratio (OR) 4.1, 95\% confidence interval (CI) $1.83-9.22, \mathrm{P}=0.001]$ and prolonged operation time $(>6 \mathrm{~h})$ (OR 5.6, 95\%CI 1.84-16.99, $\mathrm{P}=0.002$ ) to be independent risk factors for in-hospital mortality. Concerning other clinical variables, including the average ICU and hospital stays, as well as postoperative complications, there were no significant between-group differences.

Postoperative CT findings are shown in Table 4. In both groups, the most enlarged segment of the thoracic aorta on the CT scan was the aortic arch; this was followed by the aortic base, proximal descending aorta, and distal descending aorta. Although there was no significant between-group difference in the diameter of the thoracic aorta, the postoperative distal aortic patency rate was significantly higher in the younger group $(\mathrm{P}=0.003)$. We then compared the postoperative distal 


\begin{tabular}{|c|c|c|c|}
\hline & $\begin{array}{c}\text { Younger group } \\
\text { Age } \leq 45 \text { years } \\
(n=30)\end{array}$ & $\begin{array}{l}\text { Older group } \\
\text { Age }>45 \text { years } \\
(n=325)\end{array}$ & $P$ value \\
\hline \multicolumn{4}{|l|}{ Cannulation site } \\
\hline Subclavian artery & $13(43.3)$ & $119(36.6)$ & NS \\
\hline Femoral artery & $11(36.7)$ & $149(45.8)$ & NS \\
\hline Subclavian+femoral arteries & $6(20.0)$ & 55 (16.9) & NS \\
\hline Ringed graft insertion & $2(6.7)$ & $14(4.3)$ & NS \\
\hline \multicolumn{4}{|l|}{ Distal replacement } \\
\hline Ascending aorta/hemiarch & 25 (83.3) & $262(80.6)$ & NS \\
\hline Ascending aorta + aortic arch & $3(10.0)$ & $49(15.1)$ & NS \\
\hline \multicolumn{4}{|l|}{ Proximal reconstruction } \\
\hline Valve re-suspension & $19(63.3)$ & $300(92.3)$ & $<0.001$ \\
\hline Modified Bentall procedure & $8(26.7)$ & $9(2.8)$ & $<0.001$ \\
\hline Separate valve replacement & $1(3.3)$ & $2(0.6)$ & NS \\
\hline CABG & $0(0)$ & $29(8.9)$ & NS \\
\hline Cardiopulmonary bypass time (min) & $172.5 \pm 47.2$ & $147.3 \pm 60.9$ & 0.031 \\
\hline Myocardial ischemia time (min) & $119.0 \pm 41.9$ & $100.9 \pm 39.9$ & 0.021 \\
\hline Operation time (min) & $434.3 \pm 139.5$ & $377.7 \pm 129.2$ & 0.025 \\
\hline Lowest body temperature $\left({ }^{\circ} \mathrm{C}\right)$ & $21.2 \pm 2.4$ & $21.2 \pm 2.3$ & NS \\
\hline Resection of the intimal tear & $21(70.0)$ & $236(72.6)$ & NS \\
\hline
\end{tabular}

Values shown are number (and percentage) of patients or mean units $\pm S D$.

$\mathrm{CABG}$, coronary artery bypass grafting.

\begin{tabular}{|c|c|c|c|}
\hline & $\begin{array}{c}\text { Younger group } \\
\text { Age } \leq 45 \text { years } \\
(n=30)\end{array}$ & $\begin{array}{l}\text { Older group } \\
\text { Age }>45 \text { years } \\
(n=325)\end{array}$ & $P$ value \\
\hline In-hospital mortality & $5 / 30(16.7 \%)$ & $28 / 325(8.6 \%)$ & NS \\
\hline Length of ICU stay (days) & $8.0 \pm 10.7$ & $6.8 \pm 5.1$ & NS \\
\hline Length of hospital stay (days) & $29.3 \pm 17.6$ & $25.5 \pm 21.2$ & NS \\
\hline \multicolumn{4}{|l|}{ Complications } \\
\hline Neurological deficits & $2(6.7 \%)$ & $25(7.7 \%)$ & NS \\
\hline Postoperative shock treated with ECLS & $1(3.3 \%)$ & $10(3.1 \%)$ & NS \\
\hline Re-exploration for bleeding & $5(16.7 \%)$ & $18(5.5 \%)$ & NS \\
\hline Prolonged mechanical ventilation $(>48 \mathrm{~h})$ & $9(30.0 \%)$ & $118(37.2 \%)$ & NS \\
\hline Tracheostomy & $1(3.3 \%)$ & $6(1.8 \%)$ & NS \\
\hline Late cardiac tamponade & $4(13.3 \%)$ & $20(6.2 \%)$ & NS \\
\hline Deep sternal wound infection & $0(0 \%)$ & $1(0.3 \%)$ & NS \\
\hline Cause of death within 30 days & $\mathrm{n}=5$ & $\mathrm{n}=28$ & \\
\hline Cardiac failure & $2(40.0 \%)$ & $13(46.4 \%)$ & NS \\
\hline Postoperative rupture of aorta & $1(20.0 \%)$ & $6(21.4 \%)$ & NS \\
\hline Multiple organ failure & $2(40.0 \%)$ & $5(17.9 \%)$ & NS \\
\hline Bleeding & $0(0 \%)$ & $2(7.1 \%)$ & NS \\
\hline Brain damage & $0(0 \%)$ & $2(7.1 \%)$ & NS \\
\hline
\end{tabular}

Values shown are number (and percentage) of patients or mean units $\pm S D$.

ICU, intensive care unit; ECLS, extracorporeal life support.

aortic patency rate in relation to resection of the intimal tear between the 2 groups. Even after resection of the intimal tear, the younger group had a significantly higher false lumen patency rate $(\mathrm{P}=0.005)$.

During the follow-up period, 4 patients in the younger group and 58 patients in the older group died. The causes of late death are shown in Table 5. The leading cause of late death in the younger group was ruptured aortic aneurysm; this was followed by renal failure. In the older group, the leading cause of late death was malignancy, followed by cardiac failure, stroke, ruptured aortic aneurysm, and respiratory failure.

Actuarial survival for all patients calculated from the time of surgery was $76.6 \pm 2.5 \%$ and $62.8 \pm 3.7 \%$ at 5 and 10 years, respectively. Cox proportional hazards regression analysis showed that a postoperative distal aorta $>45 \mathrm{~mm}$ [hazard ratio (HR) $2.1,95 \% \mathrm{CI} 1.48-2.99, \mathrm{P}=0.001]$, ringed graft insertion $(\mathrm{HR}=20.7,95 \% \mathrm{CI} 2.86-150.1, \mathrm{P}=0.003)$, and age (HR $1.01 /$ year, 95\%CI $1.000-1.023 \mathrm{P}=0.044)$ were independent risk factors for late death. Preoperative characteristics, post- 


\begin{tabular}{|c|c|c|c|}
\hline & $\begin{array}{c}\text { Younger group } \\
\text { Age } \leq 45 \text { years } \\
(n=24)\end{array}$ & $\begin{array}{l}\text { Older group } \\
\text { Age }>45 \text { years } \\
(n=285)\end{array}$ & $P$ value \\
\hline \multicolumn{4}{|l|}{ Aortic diameter $(\mathrm{cm})$} \\
\hline Base & $36.4 \pm 6.9$ & $35.4 \pm 4.8$ & NS \\
\hline Aortic arch & $37.5 \pm 5.7$ & $39.8 \pm 5.6$ & NS \\
\hline Proximal descending aorta & $36.3 \pm 7.6$ & $33.8 \pm 5.5$ & NS \\
\hline Distal descending aorta & $31.6 \pm 7.5$ & $31.6 \pm 5.8$ & NS \\
\hline Patent false lumen & $91.6 \%(22 / 24)$ & $59.3 \%(167 / 285)$ & 0.003 \\
\hline Resection of the intimal tear & $94.4 \%(17 / 18)$ & $57.8 \%(122 / 211)$ & 0.005 \\
\hline Unresection of the intimal tear & $83.3 \%(5 / 6)$ & $60.8 \%(45 / 74)$ & 0.276 \\
\hline
\end{tabular}

Values shown are mean units \pm SD or percentage and ratio or number of patient. $\mathrm{CT}$, computed tomography.

\begin{tabular}{|lccc|}
\hline Table 5. Causes of Late Death per Study Group & Younger group \\
Cause of death & $\begin{array}{c}\text { Age } \mathbf{4 4 5} \text { year } \\
(\mathbf{n = 4 )}\end{array}$ & $\begin{array}{c}\text { Older group } \\
\text { Age }>\mathbf{4 5} \text { years } \\
(\mathbf{n}=\mathbf{5 8})\end{array}$ & P value \\
Malignancy & $0(0 \%)$ & $16(27.6 \%)$ & NS \\
Cardiac failure & $0(0 \%)$ & $10(17.2 \%)$ & NS \\
Stroke & $0(0 \%)$ & $8(13.8 \%)$ & NS \\
Ruptured aortic aneurysm & $3(75 \%)$ & $6(10.3 \%)$ & 0.005 \\
Respiratory failure & $0(0 \%)$ & $6(10.3 \%)$ & NS \\
Sudden death & $0(0 \%)$ & $3(5.2 \%)$ & NS \\
Gl tract bleeding & $0(0 \%)$ & $3(5.2 \%)$ & NS \\
Renal failure & $1(25 \%)$ & $2(3.4 \%)$ & NS \\
Sepsis & $0(0 \%)$ & $2(3.4 \%)$ & NS \\
Motor vehicle accident & $0(0 \%)$ & $1(1.7 \%)$ & NS \\
Unknown & $0(0 \%)$ & $1(1.7 \%)$ & NS \\
Total & $4(100 \%)$ & $58(100 \%)$ & \\
\hline
\end{tabular}

GI, gastrointestinal.

operative complications, patency of the false lumen, and postoperative medications were not associated with late death. Actuarial survival for the younger group $(n=29)$ was $70.3 \pm$ $8.9 \%$ and $64.5 \pm 9.9 \%$ at 5 and 10 years, respectively, and that for the older group $(n=323)$ was $77.2 \pm 2.6 \%$ and $62.5 \pm 4.0 \%$ at 5 and 10 years, respectively. Long-term survival was similar between groups, with no statistical difference (Figure 1). When we examined long-term survival of young patients with $(n=8)$ and without MFS $(n=21)$, actuarial survival from the time of surgery for those with MFS was $62.5 \pm 17.1 \%$ and $50.0 \pm 17.7 \%$ at 5 and 10 years, respectively, and that for those without MFS was $72.4 \pm 10.7 \%$ at both 5 and 10 years. There was no significant difference in long-term survival between young patients with and without MFS $(\mathrm{P}=0.24)$.

During the follow-up period, 28 patients $(8.8 \%)$ underwent 32 late aortic reoperations, including 7 reoperations on the proximal aorta and 25 reoperations on the distal aorta. One patient underwent both proximal and distal aortic reoperations. Freedom from aortic reoperations for all survivors was $97.3 \pm 1.0 \%$ at 1 year, $94.3 \pm 1.5 \%$ at 5 years, and $82.0 \pm 4.0 \%$ at 10 years. Indications for the 7 proximal aortic reoperations included severe aortic insufficiency in 6 patients and graft infection in 1. Our criterion for distal aortic reoperation was an aortic diameter $>60 \mathrm{~mm}$. The 25 distal aortic reoperations included 11 total arch replacements, 10 descending thoracic aorta replacements, and 4 thoracoabdominal aorta replacements. Three patients underwent 2 distal aortic reoperations each. Thirty of the 32 reoperations were performed electively. There was no perioperative death associated with these reoperations. Cox proportional hazards regression analysis showed a postoperative distal aorta $>45 \mathrm{~mm}$ (HR 4.9, 95\% CI 2.3-11.5, $\mathrm{P}<0.001$ ), MFS (HR 30.3, 95\%CI 3.2-250.0, $\mathrm{P}=$ 0.002 ), and younger age (HR 0.96/year, 95\%CI 0.92-0.99, $\mathrm{P}=0.028$ ) to be independent risk factors for late aortic reoperation. Extensive distal resection was not associated with late reoperation. A patent false lumen was found by univariable analysis to be a risk factor for late reoperation [patent false lumen group; $11.9 \%(22 / 185)$ vs. thrombosed false lumen group; $5.0 \%$ (6/120), $\mathrm{P}=0.042$ ], but it was not identified as an independent risk factor by Cox proportional hazards regression analysis $(\mathrm{P}=0.48)$.

Freedom from aortic reoperation in the younger group $(\mathrm{n}=$ 24) was $79.0 \pm 9.4 \%$ and $49.4 \pm 17.8 \%$ at 5 and 10 years, respectively, and that in the older group $(n=295)$ was $95.4 \pm 1.4 \%$ and $85.0 \pm 3.8 \%$ at 5 and 10 years, respectively; the difference was significant $(\mathrm{P}=0.012)$ (Figure 2). When we examined freedom from aortic reoperation among young patients with $(\mathrm{n}=5)$ and without MFS $(\mathrm{n}=17)$, actuarial freedom from aortic reoperation for those with MFS was $60.0 \pm 21.9 \%$ and $0 \%$ at 5 and 10 years, respectively, and that for those without MFS was $87.4 \pm 8.4 \%$ and $65.5 \pm 19.9 \%$ at 5 and 10 years, respectively. The decrease in the MFS group was not significant $(\mathrm{P}=0.066)$.

Finally, we investigated freedom from aortic events for all 


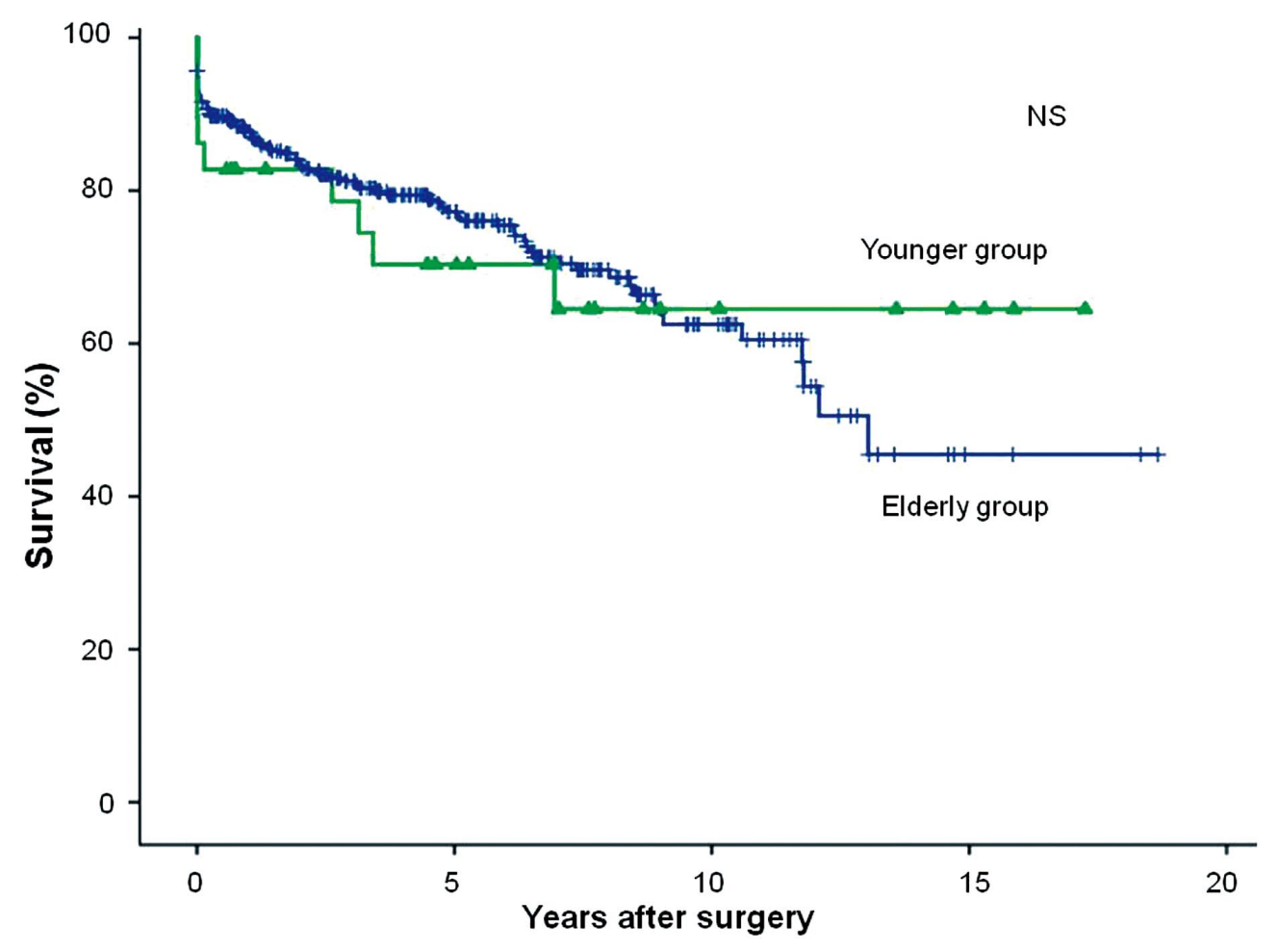

Figure 1. Kaplan-Meier curves. Actuarial survival in younger ( $\leq 45$ years) and older ( $>45$ years) patients with $A A A D$ (including in-hospital deaths). AAAD, acute type A aortic dissection.

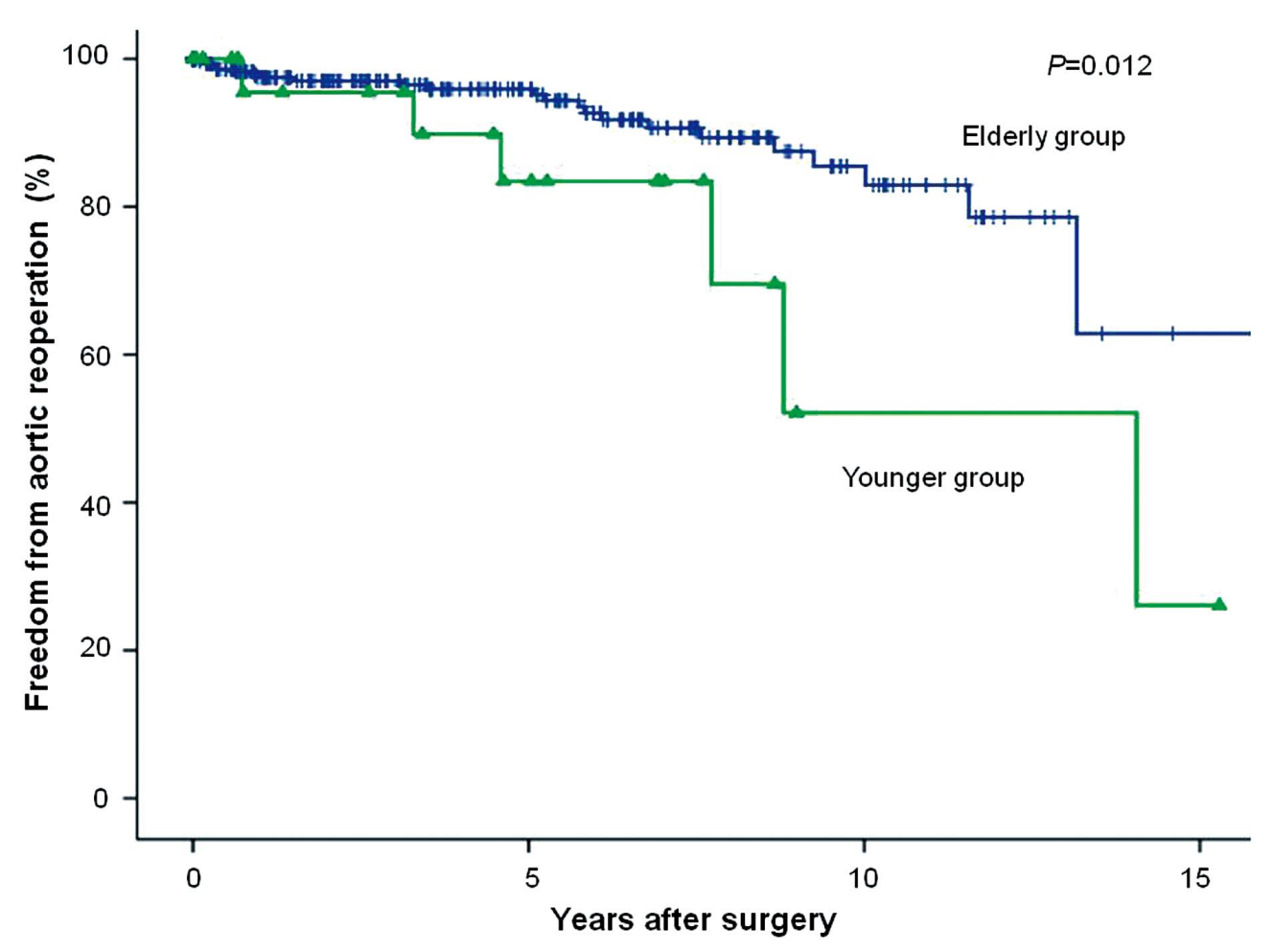

Figure 2. Freedom from aortic reoperation in younger ( $\leq 45$ years) and older ( $>45$ years) patients with $A A A D$. AAAD, acute type A aortic dissection. 


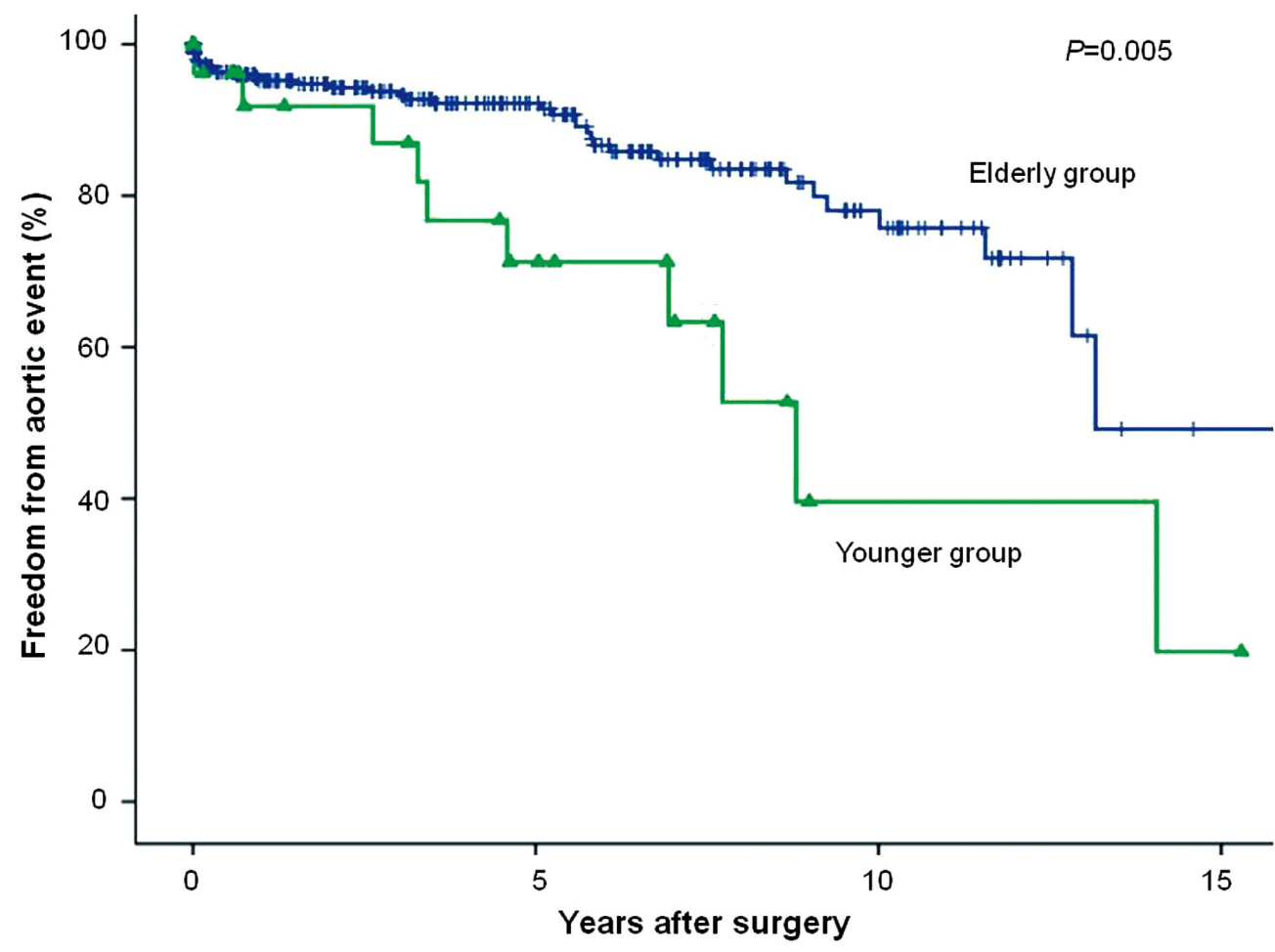

Figure 3. Freedom from aortic events in younger ( $\leq 45$ years) and older ( $>45$ years) patients with AAAD. AAAD, acute type $A$ aortic dissection.

patients $(n=352)$, except the 3 patients for whom follow-up information was not obtained. Aortic events included in-hospital death due to early aortic rupture $(n=7)$, late aortic rupture or re-dissection $(n=6)$, proximal and/or distal aortic reoperation $(n=28)$, and surgery for abdominal aortic aneurysm $(n=$ 4). Cox proportional hazards regression analysis showed postoperative distal aorta $>45 \mathrm{~mm}$ (HR 4.8, 95\% CI 2.5-9.3, $\mathrm{P}<0.001$ ), MFS (HR 15.6, 95\%CI 2.2-11.1, $\mathrm{P}=0.006$ ), and younger age (HR 0.96/year, 95\%CI $0.93-0.99, \mathrm{P}=0.01$ ) to be independent risk factors for postoperative aortic reoperation. A patent false lumen was shown by univariate analysis to be a risk factor for late aortic events [patent false lumen group; $16.2 \%$ (30/185) vs. thrombosed false lumen group; $8.3 \%(10 / 120), \mathrm{P}=0.046]$, but it was not identified as an independent risk factor by Cox proportional hazards regression analysis $(\mathrm{P}=0.71)$.

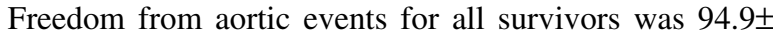
$1.2 \%$ at 1 year, $90.2 \pm 1.9 \%$ at 5 years, and $73.8 \pm 4.3 \%$ at 10 years. Freedom from aortic events in the younger group $(n=29)$ was $71.2 \pm 10.1 \%$ and $39.6 \pm 15.4 \%$ at 5 and 10 years, respectively, and that for the older group $(n=323)$ was $92.2 \pm$ $1.7 \%$ and $78.0 \pm 4.2 \%$ at 5 and 10 years, respectively; the difference was significant $(\mathrm{P}=0.005)$ (Figure 3).

\section{Discussion}

In a 2004 analysis based on the IRAD data, ${ }^{6}$ Januzzi et al reported that $50 \%(34 / 68)$ of patients $<40$ years of age were diagnosed with MFS, and patients $<40$ years of age were less likely than older patients to have a prior history of hypertension. Although MFS was significantly more prevalent in our younger group than in our older group, the prior history of hypertension was similar between the 2 groups. However, male sex and current smoking were significantly more prevalent in our younger group. According to other previously reported IRAD data, female patients with acute aortic dissection were significantly older than male patients with acute aortic dissection (mean age of females, 66.7 years vs. mean age of males, 60.3 years, $\mathrm{P}<0.001) ;{ }^{17}$ our findings are consistent with these data.

Marfan syndrome is a heritable connective tissue disorder with a prevalence of 1 in 3,000-5,000 individuals. ${ }^{8}$ The life expectancy of MFS patients has improved dramatically; between 1972 and 1995, the median cumulative probability of survival was extended from 48 years to 72 years. ${ }^{11}$ Three of our 8 young patients with MFS died in the hospital; that is, 5 survived after the initial surgery for AAAD. All 5 of these patients underwent composite valve-graft replacement, and none required later proximal aortic reoperation. However, 3 of the 5 patients underwent distal aortic reoperation at a mean 5.2 years after the initial surgery, and 1 patient died of distal aortic rupture 6.9 years after the initial surgery for AAAD. Regarding distal aortic dissection in patients with MFS, Carrel et al reported that 14 of 71 (20.5\%) patients with MFS who had undergone surgery for annulo-aortic ectasia subsequently underwent a total of 27 aortic reoperations during a mean follow-up period of 5.2 years. ${ }^{12}$ More importantly, initial aortic root surgery was performed for AAAD in 13 of the 14 patients. The long-term outcome of aortic root replacement in MFS patients differs between those who undergo surgery for aortic dissection and those without dissection because patients with MFS tend to require multi- 
ple surgical interventions if chronic dissection remains in the native distal aorta. In such cases, patients should be placed under aggressive imaging surveillance because sudden and catastrophic changes can occur unexpectedly even when the aorta is not markedly enlarged. ${ }^{8}$

A bicuspid aortic valve is the most common congenital cardiac abnormality in the adult population. ${ }^{18}$ Although Januzzi et al reported a high prevalence of bicuspid aortic valve among young patients with AAAD $(9 \%, 6 / 68),{ }^{6}$ bicuspid aortic valve was diagnosed in only 1 female in our group of young patients $(3 \%, 1 / 30)$. Thus, it remains unclear whether the bicuspid aortic valve should be managed aggressively to protect patients from aortic dilation and dissection. The reported risk of aortic complications is high, particularly when aortic dilation is present at the time of the initial diagnosis of a bicuspid aortic valve. ${ }^{19}$ Therefore, such patients might require regular assessment, including imaging surveillance. Regarding other disorders that promote acute aortic dissection in young patients, other connective tissue diseases, such as vascular Ehler-Danlos syndrome, Loeys-Dietz syndrome, ${ }^{20}$ and Turner syndrome, ${ }^{21}$ as well as cocaine use ${ }^{22}$ have been reported as possible underlying conditions.

The IRAD study documented similar overall in-hospital mortality and morbidity rates between young and older patients with AAAD. ${ }^{6}$ Similarly, we found no statistical difference in short-term outcomes between our 2 groups, although the in-hospital mortality rate was higher in our younger group than in our older group. Preoperative patient status is reported to be directly related to surgical outcome. ${ }^{23}$ With the exception of severe aortic regurgitation, preoperative patient hemodymamics, organ malperfusion, and dissection characteristics were similar between our 2 study groups. However, the average cardiopulmonary bypass time, myocardial ischemia time, and operation time were significantly longer in the younger group than in the older group. One of the main reasons for this difference was the high frequency of aortic root surgery in the younger group. A previous study showed that aortic root surgery for AAAD does not increase the risk of death, ${ }^{24}$ and we believe that aortic root surgery is mandatory for patients with a dilated aortic root, even in the emergency AAAD setting. However, in addition to preoperative shock, prolonged operation time $(>6 \mathrm{~h})$ was identified as an independent risk factor for in-hospital death in our patient series. Prolonged surgery for patients at risk of death might increase the already high operative risk through coagulopathy, cerebral ischemia, infection, or multiple organ failure. Therefore, we might need to do all that is possible to decrease the operation time for patients undergoing such an invasive procedure. Application of a hemostatic agent such as fibrin glue could be an effective treatment option toward this aim. ${ }^{25}$

A residual patent false lumen is a well-known risk factor for rapid aortic enlargement in patients with chronic aortic dissection..$^{26}$ The incidence of residual patent false lumen in the distal aorta was $61.1 \%$ (189/309) among our study patients. Although this incidence accorded with results of previous studies (43-78\%) in which aortic arch replacement was performed in selected patients, ${ }^{26-30}$ it was higher than the 27$46 \%$ incidence of residual patent false lumen reported by other groups that used aortic arch grafting in all patients with AAAD extending to the descending aorta.,31,32 We encountered 7 patients with early postoperative aortic rupture, and the intimal tear was not resected in 2 of these 7 patients due to IIIb retrograde AAAD. Although we did not find residual patent false lumen to be an independent risk factor for in-hospital mortality and long-term events, it was shown to influence both aortic reoperation and postoperative aortic events. Januzzi et al reported that a patent false lumen was found more often in younger patients with AAAD than in older patients, ${ }^{6}$ and we confirmed this finding. Although the reason why age $\leq 45$ years is associated with a residual patent false lumen is unknown, the higher false lumen patency rate in the younger group seems to be clearly associated with the higher incidence of distal aortic rupture and reoperation during the follow-up period. Therefore, we think that when young patients are in a stable condition, total aortic arch replacement is a preferable operative approach because it not only reduces the likelihood of a patent false lumen but also prevents fatal aortic events.

The decision to perform repeat surgical intervention to prevent rupture in the distal aorta in stable, asymptomatic patients is another important issue. As mentioned above, the results of distal aorta reoperations were satisfactory (no perioperative deaths among 32 patients who underwent reoperation). In addition, the most common cause of late mortality in young patients with AAAD was distal aortic rupture. Thus, we believe that timely reoperation can improve long-term survival in such patients. Previously, we had applied $60 \mathrm{~mm}$ as a size criterion for surgical treatment of chronic type B aortic dissection; however, we think that distal aortic reoperation should be performed when the aortic diameter reaches $55 \mathrm{~mm}$ in otherwise healthy young patients with a patent false lumen.

Like all retrospective studies, this investigation has some limitations. First, the group of young patients, defined as patients aged $\leq 45$ years, included both truly young patients with connective tissue disease and patients in their early $40 \mathrm{~s}$ who had hypertension. Although the difference did not reach statistical significance, freedom from aortic reoperation was decreased among our young patients with MFS in comparison to that among our young patients without MFS. However, the aim of our study was to reveal in-hospital and long-term outcomes after surgery for AAAD in young patients, regardless of the underlying etiology. In general, the number of aortic pathologies treated on a hospital-to-hospital basis is limited. Thus, little is known about the patient characteristics, surgical results, and postoperative outcomes of young patients with AAAD. Januzzi et al reported the largest number of young patients with AAAD using data from the IRAD registry. ${ }^{6}$ We referred mainly to this IRAD study and applied nearly the same patient selection criteria to our study. The sole difference in patient selection between the IRAD study and ours is the cut-off age of the younger group; Januzzi et al used 40 years as the cut-off. Although we used 45 years as the cut-off to increase the number of patients in our younger group, encountering AAAD in patients in their early $40 \mathrm{~s}$ is uncommon in daily clinical practice. Therefore, we believe that our findings have strong implications in terms of perioperative management and long-term follow up after surgery for AAAD in young patients. Second, our young patient group was small. Further studies involving larger numbers of patients are needed. Finally, we routinely perform an initial postoperative enhanced CT examination within 1 month after the initial surgery; however, we did not check the aortic growth rate in the patients described herein. Follow-up CT examinations after discharge were not standardized between our hospital and the neighboring hospitals. Therefore, we were unable to evaluate long-term changes in the diameters of the true and false lumens.

In conclusion, our findings suggest that the risk of late adverse aortic events might be increased in young patients with 
$\mathrm{AAAD}$, and the increased false lumen patency rate in the younger patients seems to be associated with the increased incidence of distal aortic events during the follow-up period. We recommend that all young patients with AAAD undergo the same thorough postoperative surveillance as MFS patients.

\section{Disclosures}

The authors have no conflict of interest to disclose.

\section{References}

1. Suzuki T. Cardiovascular diagnostic biomarkers: The past, present and future. Circ J 2009; 73: 806-809.

2. Kurabayashi M, Okishige K, Azegami K, Ueshima D, Sugiyama K, Shimura T, et al. Reduction of the $\mathrm{PaO}_{2} / \mathrm{FiO}_{2}$ ratio in acute aortic dissection: Relationship between the extent of dissection and inflammation. Circ J 2010; 74: 2066-2073.

3. Westaby S, Saito S, Katsumata T. Acute type A dissection: Conservative methods provide consistently low mortality. Ann Thorac Surg 2002; 73: 707-713.

4. Takahara Y, Sudo Y, Mogi K, Nakayama M, Sakurai M. Total aortic arch grafting for acute type A dissection: Analysis of residual false lumen. Ann Thorac Surg 2002; 73: 450-454.

5. Puranik R, Chow CK, Duflou JA, Kilborn MJ, McGuire MA. Sudden death in the young. Heart Rhythm 2005; 2: 1277-1282.

6. Januzzi JL, Isselbacher EM, Fattori R, Cooper JV, Smith DE, Fang J, et al. Characterizing the young patient with aortic dissection: Results from the International Registry of Aortic Dissection (IRAD). J Am Coll Cardiol 2004; 43: 665-669.

7. Nienaber CA, Eagle KA. Aortic dissection: New frontiers in diagnosis and management: Part I: From etiology to diagnostic strategies. Circulation 2003; 108: 628-635.

8. Milewicz DM, Dietz HC, Miller DC. Treatment of aortic disease in patients with Marfan syndrome. Circulation 2005; 111: e150e157.

9. Shores J, Berger KR, Murphy EA, Pyeritz RE. Progression of aortic dilatation and the benefit of long-term beta-adrenergic blockade in Marfan's syndrome. N Engl J Med 1994; 330: 1335-1341.

10. Coselli JS, LeMaire SA. Current status of thoracoabdominal aortic aneurysm repair in Marfan syndrome. J Card Surg 1997; 12(2 Suppl): $167-172$

11. Silverman DI, Burton KJ, Gray J, Bosner MS, Kouchoukos NT, Roman MJ, et al. Life expectancy in the Marfan syndrome. Am J Cardiol 1995; 75: 157-160.

12. Carrel T, Beyeler L, Schnyder A, Zurmühle P, Berdat P, Schmidli J, et al. Reoperations and late adverse outcome in Marfan patients following cardiovascular surgery. Eur J Cardiothorac Surg 2004; 25: $671-675$.

13. Neri E, Toscano T, Massetti M, Capannini G, Carone E, Tucci E, et al. Operation for acute type A aortic dissection in octogenarians: Is it justified? J Thorac Cardiovasc Surg 2001; 121: 259-267.

14. Kawahito K, Adachi H, Yamaguchi A, Ino T. Early and late surgical outcomes of acute type A aortic dissection in patients aged 75 years and older. Ann Thorac Surg 2000; 70: 1455-1459.
15. Chiappini B, Tan ME, Morshuis W, Kelder H, Dossche K, Schepens M. Surgery for acute type A aortic dissection: Is advanced age a contraindication? Ann Thorac Surg 2004; 78: 585-590.

16. Kimura N, Tanaka M, Kawahito K, Yamaguchi A, Ino T, Adachi $\mathrm{H}$. Early postoperative aortic rupture following surgery for acute type A aortic dissection. Interact Cardiovasc Thorac Surg 2009; 8: $431-434$.

17. Nienaber CA, Fattori R, Mehta RH, Richartz BM, Evangelista A, Petzsch M, et al. Gender-related difference in acute aortic dissection. Circulation 2004; 109: 3014-3021.

18. Tutar E, Ekici F, Atalay S, Nacar N. The prevalence of bicuspid aortic valve in newborns by echocardiographic screening. Am Heart $J$ 2005; 150: $513-515$.

19. Michelena HI, Desjardins VA, Avierinos JF, Russo A, Nkomo VT, Sundt TM, et al. Natural history of asymptomatic patients with normally functioning or minimally dysfunctional bicuspid aortic valve in the community. Circulation 2008; 117: 2776-2784.

20. Melenovsky V, Adamira M, Kautznerova D, Voska L, Weichet J, Loeys B, et al. Aortic dissection in a young man with Loeys-Dietz syndrome. J Thorac Cardiovasc Surg 2008; 135: 1174-1175.

21. Bondy CA. Aortic dissection in Turner syndrome. Curr Opin Cardiol 2008; 23: 519-526.

22. Eagle KA, Isselbacher EM, DeSanctis RW; International Registry for Aortic Dissection (IRAD) Investigators. Cocaine-related aortic dissection in perspective. Circulation 2002; 105: 1529-1530.

23. Long SM, Tribble CG, Raymond DP, Fiser SM, Kaza AK, Kern JA, et al. Preoperative shock determine outcome for acute type A aortic dissection. Ann Thorac Surg 2003; 75: 520-524.

24. Ergin MA, McCullough J, Galla JD, Lansman SL, Griepp RB. Radical replacement of the aortic root in acute type A dissection: Indications and outcome. Eur J Cardiothorac Surg 1996; 10: 840845.

25. Minato N, Katayama Y, Yunoki J, Kawasaki H, Satou H. Hemostatic effectiveness of a new application method for fibrin glue, the "rub-and-spray method", in emergency aortic surgery for acute aortic dissection. Ann Thorac Cardiovasc Surg 2009; 15: 265-271.

26. Halstead JC, Meier M, Etz C, Spielvogel D, Bodian C, Wurm M, et al. The fate of the distal aorta after repair of acute type A aortic dissection. J Thorac Cardiovasc Surg 2007; 133: 127-135.

27. Immer FF, Hagen U, Berdat PA, Eckstein FS, Carrel TP. Risk factors for secondary dilation of the aorta after acute type A aortic dissection. Eur J Cardiothorac Surg 2005; 27: 654-657.

28. Fann JI, Smith JA, Miller DC, Mitchell RS, Moore KA, Grunkemeier $\mathrm{G}$, et al. Surgical management of aortic dissection during a 30-year period. Circulation 1995; 92(9 Suppl): II113-II121.

29. David TE, Armstrong S, Ivanov J, Barnard S. Surgery for acute type A aortic dissection. Ann Thorac Surg 1999; 67: 1999-2001.

30. Fattori R, Bacchi-Reggiani L, Bertaccini P, Napoli G, Fusco F, Longo M, et al. Evolution of aortic dissection after surgical repair. Am J Cardiol 2000; 86: 868-872.

31. Urbanski PP, Siebel A, Zacher M, Hacker RW. Is extended aortic replacement in acute type A dissection justifiable? Ann Thorac Surg 2003; 75: 525-529.

32. Hirotani T, Nakamichi T, Munakata M, Takeuchi S. Routine extended graft replacement for an acute type A aortic dissection and the patency of the residual false channel. Ann Thorac Surg 2003; 76: $1957-1961$ 